\title{
KARAKTERISASI PELEPASAN NITRAT PADA ANDISOL DI JAWA BARAT DAN
} JAWA TENGAH

\section{Characterization of Nitrate Release on Andisols in West and Central Java}

\author{
Arief Hartono ${ }^{1)^{*}}$, Syaiful Anwar1) dan Novianti Ruliana2) \\ 1) Departemen Ilmu Tanah dan Sumbedaya Lahan, Fakultas Pertanian IPB University, Jl. Meranti \\ Kampus IPB Dramaga Bogor 16680 \\ 2) Program Studi Manajemen Sumberdaya Lahan, Departemen Ilmu Tanah dan Sumbedaya Lahan, \\ Fakultas Pertanian IPB University, J1. Meranti Kampus IPB Dramaga Bogor 16680
}

\begin{abstract}
The area of Andisols in Indonesia is about 5.4 million hectares. This soil is used extensively by farmers for horticulture and tea plantation, and to a small portion for livestock. The characteristics of nitrate release are very specific location so that it is necessary to reveal soil properties affecting the pattern of nitrate release on Andisols in West and Central Java. The objectives of the research were to characterize chemical properties of Andisols, characterize parameters of nitrate release on Andisols, and obtain the correlation between chemical properties and the parameters of nitrate release on Andisols in West and Central Java. The experiment of nitrate release was conducted by incubation experiment, then simulated using first-order kinetic. Soil analyses revealed that there was a variation of chemical properties among Andisols in West and Central Java. The release of nitrate on Andisols from Lembang, Pangalengan, Sukamantri and Dieng, in general, decreased with the increase of soil depth in one soil profile and increased with the period of incubation times. A simple correlation test showed that the potential nitrate release $\left(N_{0}\right)$ had correlations that were not significant with the analyzed soil properties. However, $N_{0}$ positively correlated with organic $C$, total $N$, oxalate-Fe, dithionite-Al and dithionite-Fe. On the other hand, the $N_{0}$ negatively correlated with oxalate-Al and $\mathrm{Al}_{o}+1 / 2 \mathrm{Fe}_{\mathrm{o}}$. As for the rate constant $(k)$, all those properties negatively correlated with $k$ value except with dithionite-Fe which had a positive correlation. It suggested that there is a possibility that nitrate release increased with the increase of the content of soil organic $C$ and total $N$ however decreased with the increase of $A l_{o}+1 / 2 F e_{o} . A l_{o}+1 / 2 F e_{o}$ also possibly decreased the rate constant of nitrate release.
\end{abstract}

Keywords: Andisols, nitrate release, soil chemical properties

\section{ABSTRAK}

Andisol tersebar luas di Indonesia dengan luas total mencapai 5.4 juta ha. Tanah-tanah ini digunakan secara luas oleh petani sebagian besar untuk pertanian hortikultura dan perkebunan teh, dan sebagian kecil untuk peternakan. Karakteristik pola pelepasan anion nitrat sangat spesifik lokasi sehingga perlu diteliti lebih jauh sifat-sifat kimia tanah apa saja yang berpengaruh terhadap pola pelepasan nitrat pada Andisol di Jawa Barat dan Jawa Tengah. Tujuan dari penelitian ini adalah: (i) mengkarakterisasi sifat kimia Andisol, (ii) mengkarakterisasi pola pelepasan nitrat pada Andisol dengan sifat kimia yang berbeda, (iii) mendapatkan hubungan antara sifat-sifat kimia tanah dengan pola pelepasan nitrat pada Andisol di Jawa Barat dan Jawa Tengah. Percobaan pelepasan nitrat dilakukan dengan metode inkubasi. Jumlah nitrat yang terlepaskan dalam penelitian ini disimulasikan dengan menggunakan persamaan first order kinetic. Berdasarkan hasil analisis, sifat-sifat kimia tanah Andisol di Jawa Barat dan Jawa Tengah bervariasi. Pelepasan nitrat pada Andisol Lembang, Pangalengan, Sukamantri, dan Dieng secara umum semakin menurun dengan meningkatnya kedalaman tanah pada satu profil tanah dan semakin meningkat dengan meningkatnya waktu inkubasi. Hasil uji korelasi sederhana menunjukkan bahwa untuk nitrat maksimum yang dapat dilepaskan $\left(\mathrm{N}_{0}\right)$ memiliki korelasi yang tidak nyata dengan sifat-sifat kimia tanah yang dianalisis. Hal ini menunjukkan bahwa nitrat sangat mobil di dalam tanah. Walaupun demikian $\mathrm{N}_{0}$ berkorelasi positif dengan $\mathrm{C}$ organik, $\mathrm{N}$ total, Fe-oksalat $\left(\mathrm{Fe}_{\mathrm{o}}\right)$, Al-dithionite dan Fe-dithionite. Sebaliknya $N_{o}$ berkorelasi negatif dengan Al-oksalat $\left(\mathrm{Al}_{0}\right)$, dan $\mathrm{Al}_{0}+1 / 2 \mathrm{Fe}_{\mathrm{o}}$. Untuk konstanta kecepatan pelepasan nitrat $(k)$ berkorelasi negatif dengan semua sifat tanah tersebut kecuali dengan dengan Fe-dithionite yang mempunyai korelasi positif. Hasil ini menyimpulkan bahwa pelepasan nitrat pada Andisol punya kemungkinan meningkat dengan meningkatnya kadar $\mathrm{C}$ organik dan $\mathrm{N}$ total tanah akan tetapi menurun dengan meningkatnya $\mathrm{Al}_{\mathrm{o}}+1 / 2 \mathrm{Fe}_{\mathrm{o}} \cdot \mathrm{Al}_{\mathrm{o}}+1 / 2 \mathrm{Fe}_{\mathrm{o}}$ juga mempunyai kemungkinan menurunkan kecepatan pelepasan nitrat pada Andisol.

Kata kunci: Andisols, pelepasan nitrat, sifat kimia tanah

\section{PENDAHULUAN}

Andisol termasuk tanah yang tersebar luas di Indonesia. Luas Andisol di Indonesia mencapai 5.4 juta ha atau sekitar $2.9 \%$ wilayah daratan Indonesia (Puslittanak, 2000). Tanah-tanah ini terdapat di sekitar lereng puncak gunung berapi dan rata-rata berada pada ketinggian sekitar 2,000 sampai 2,500 meter di atas permukaan laut. Tanahtanah ini digunakan secara luas oleh petani untuk pertanian hortikultura, perkebunan teh, dan sebagian kecil untuk peternakan. 
Penggunaan pupuk urea dan kotoran ternak sebagai sumber pupuk nitrogen $(\mathrm{N})$ oleh petani sangat besar sehingga ada kekhawatiran bahwa telah terjadi pencemaran ion nitrat pada air tanah. Pengetahuan tentang kemampuan tanah dalam melepaskan nitrat menjadi sangat penting dalam kaitan pergerakan nitrat di dalam profil tanah sampai pada air tanah. Penelitian terdahulu Andisol di Indonesia yang terkait dengan pelepasan anion adalah penelitian tentang fosfat (Hartono et al., 2007; Hartono, 2008; Hartono dan Bilhaq, 2011). Belum banyak data penelitian tentang pelepasan nitrat di Andisol sementara nitrat di Andisol diperkirakan sangat banyak dan bergerak secara vertikal terbawa air perkolasi tanah sehingga dapat mencemari lingkungan.

Karakteristik pola pelepasan anion tererap termasuk nitrat sangat spesifik lokasi sehingga perlu dicari tahu lebih jauh sifat-sifat kimia tanah apa saja yang berpengaruh terhadap pola pelepasan nitrat pada Andisols. Karakteristik pelepasan nitrat yang ditetapkan melalui percobaan inkubasi dapat disimulasikan dengan menggunakan persamaan first order kinetics.

Tujuan dari penelitian ini adalah (i) mengkarakterisasi sifat-sifat fisiko kimia Andisols di Jawa Barat dan Jawa Tengah, (ii) mengkarakterisasi pola pelepasan nitrat pada Andisols di Jawa Barat dan Jawa Tengah dengan sifat fisikokimia yang berbeda, dan (iii) mendapatkan hubungan antara sifat-sifat kimia tanah dengan pola pelepasan nitrat pada Andisol.

\section{BAHAN DAN METODE}

Contoh Andisol diambil empat lokasi di Jawa Barat dan Jawa Tengah, yaitu Lembang, Pangalengan, Sukamantri, dan Dieng. Contoh tanah diambil pada kedalaman 0-100 cm tergantung horizon penyusun profil tanah tersebut. Secara keseluruhan terdapat 15 contoh tanah. Penelitian dilakukan di Laboratorium Kimia dan Kesuburan Tanah, Fakultas Pertanian, Institut Pertanian Bogor. Penelitian dilakukan mulai dari bulan Desember 2013 sampai April 2014.

\section{Bahan dan Alat}

Bahan yang digunakan pada penelitian ini yaitu contoh tanah yang diambil dari Andisol Lembang, Andisol Pangalengan, Andisol Sukamantri, dan Andisol Dieng serta bahan-bahan kimia untuk analisis pendahuluan dan pelepasan nitrat.

Alat yang digunakan pada penelitian ini yaitu peralatan untuk pengambilan contoh tanah di lapang, $\mathrm{pH}$ meter, pipet, kertas saring, erlenmeyer, labu Kjehdal, saringan ukuran 2-mm mesh, spektrofotometer UV-Vis, AAS (Atomic Absorbtion Spectrophotometer), flame photometer, serta alat-alat laboratorium lainnya.

\section{Analisis Sifat Fisikokimia Tanah}

Contoh-contoh tanah dikeringudarakan, ditumbuk dan disaring dengan saringan berukuran 2-mm. Nilai $\mathrm{pH}$ $\mathrm{H}_{2} \mathrm{O}$ tanah (1:5) ditetapkan menggunakan $\mathrm{pH}$ meter. Tekstur tanah ditetapkan dengan menggunakan metode pipet. Kandungan $\mathrm{C}$ organik ditetapkan dengan menggunakan metode Walkley dan Black. Kandungan P- tersedia ditetapkan dengan metode Bray I. Kandungan N total ditetapkan dengan metode Kjeldahl. Kapasitas tukar kation (KTK) ditetapkan dengan menggunakan ekstraksi 1 $M$ NH4OAc pH 7.0. Kandungan basa-basa Ca dan $\mathrm{Mg}$ pada ekstrak ditetapkan menggunakan atomic absorption spectrophotometry (AAS), sementara $\mathrm{K}$ dan Na ditetapkan menggunakan flame photometer. Kejenuhan basa (KB) adalah jumlah kation basa-basa dibagi dengan nilai KTK dikalikan dengan $100 \%$.

Oksida besi ( $\mathrm{Fe}$ ) dan aluminium ( $\mathrm{Al}$ ) yang kristalin diekstrak menggunakan pengekstrak dithionite-citratebicarbonate berdasarkan metode Mehra dan Jackson (1960). Oksida Fe dan Al ini disebut berturut-turut Fedithionite dan Al-dithionite $\left(\mathrm{Fe}_{\mathrm{d}}\right.$ dan $\left.\mathrm{Al}_{\mathrm{d}}\right)$. Oksida $\mathrm{Fe}$ dan $\mathrm{Al}$ yang amorf diekstrak dengan menggunakan $0.3 \mathrm{M}$ ammonium oxalate pada $\mathrm{pH} 3$ selama 4 jam di ruang gelap berdasarkan metode yang dikembangkan oleh McKeague dan Day (1966). Oksida Fe dan Al ini disebut berturut-turut $\mathrm{Fe}$-oksalat dan $\mathrm{Al}$-oksalat $\left(\mathrm{Fe}_{\mathrm{o}}\right.$ dan $\left.\mathrm{Al}_{\mathrm{o}}\right)$. $\mathrm{Fe}$ dan $\mathrm{Al}$ yang terekstrak selanjutnya ditetapkan dengan menggunakan atomic absorption spectrophotometer (AAS).

\section{Percobaan Pelepasan Nitrat}

Percobaan pelepasan nitrat dilakukan dengan metode inkubasi (Stanford dan Smith, 1972; Saito dan Ishii, 1987; Sano et al., 2004). Contoh tanah segar dari lapangan disaring dengan saringan $2 \mathrm{~mm}$. Kemudian contoh tanah yang telah lolos saringan $2 \mathrm{~mm}$ ditetapkan kadar ainya. Contoh tanah ditimbang sebanyak $8 \mathrm{~g}$ setara berat kering mutlak (BKM) dan dimasukkan ke dalam botol. Botol yang berisi contoh tanah diinkubasi selama 1 minggu, 2 minggu, 4 minggu, dan 6 minggu pada kondisi kapasitas lapang. Kandungan nitrat dalam tanah setelah masa inkubasi ditetapkan dengan pengekstran 1.00 M KCl. Sebanyak 5.00 g contoh tanah yang telah diinkubasi dengan waktu tertentu, dimasukkan ke dalam tabung sentrifus dan ditambahkan larutan $\mathrm{KCl} 1 \mathrm{M}$ sebanyak $25.0 \mathrm{ml}$. Setelah itu, tabung sentrifus ditempatkan pada shaker dan dikocok selama 30 menit dengan kecepatan $180 \mathrm{rpm}$. Setelah pengocokan selesai tabung-tabung sentrifus tersebut disentrifus dengan kecepatan 2,500 rpm selama 15 menit, kemudian tabungtabung sentrifus tersebut disaring untuk diambil larutannya. Larutan yang diperoleh ditampung pada botol film, untuk kemudian diukur absorbannya dengan spektrofotometer UV-Vis pada panjang gelombang $210 \mathrm{~nm}$ dan $275 \mathrm{~nm}$. Panjang gelombang $275 \mathrm{~nm}$ digunakan untuk faktor koreksi terhadap karbon (C) organik yang terlarut. Konsentrasi larutan standar nitrat yang digunakan adalah $0,1.00,2.00$, $3.00,4.00,5.00,10.00$ dan 15.00 ppm nitrat. Nitrat yang didapat dengan penetapan ini adalah nitrat yang dilepaskan oleh tanah.

Jumlah nitrat yang dilepaskan disimulasikan dengan menggunakan persamaan first order kinetics:

$$
N_{0}=N_{t} /\left\{1-\exp ^{(-k t)}\right\}
$$

dimana $N_{t}$ adalah nitrat yang dilepaskan pada setiap masa inkubasi $\left(\mathrm{mg} \mathrm{kg}^{-1}\right), t$ adalah waktu inkubasi dalam (minggu), $\quad N_{0}$ adalah nitrat maksimum yang dapat dilepaskan $\left(\mathrm{mg} \mathrm{kg}^{-1}\right)$, dan $k$ adalah konstanta kecepatan pelepasan nitrat $\left(\operatorname{minggu}^{-1}\right)$. Pengolahan data first order kinetics dilakukan dengan menggunakan software statistika SigmaPlot 12.5 . 
Analisis korelasi sederhana digunakan untuk menentukan sifat tanah yang berpengaruh terhadap nilai $N_{0}$, dan nilai $k$.

\section{HASIL DAN PEMBAHASAN}

\section{Sifat Fisikokimia Andisols}

Sifat fisikokimia contoh tanah Andisols yang diteliti disajikan pada Tabel 1. Berdasarkan nilai yang didapat, sifat fisikokimia dari 15 contoh lapisan tanah relatif sangat bervariasi.

Status sifat kimia tanah ditetapkan berdasarkan kriteria penilaian Balai Penelitian Tanah (2009). Andisol di Jawa Barat umumnya mempunyai kadar liat lebih besar dari 30\%. Nilai pH tanah Andisol Jawa Barat berkisar dari masam sampai agak masam. Kadar $\mathrm{C}$ organik umumnya sangat tinggi Kadar $\mathrm{N}$ total berkisar dari sedang sampai tinggi. $\mathrm{N}$ total dengan status tinggi ada pada kedalaman 0$20 \mathrm{~cm}$. C/N rasio umumnya kurang dari 20. Hal ini menunjukkan bahwa $\mathrm{N}$ pada Andisol sangat mudah termineralisasi. Kadar P Bray 1 umumnya sudah dalam taraf sangat tinggi. KTK umumnya masuk dalam kategori sedang sampai tinggi. Kejenuhan basa berkisar dari sangat rendah sampai rendah.

Andisol di Jawa Tengah yang diwakili oleh Andisol Dieng, mempunyai kadar liat dengan kisaran $20 \%$ sampai dengan $40 \%$. pH tanah umumnya masuk dalam status agak masam. Kadar $\mathrm{C}$ organik berkisar dari sedang sampai sangat tinggi. $\mathrm{N}$ total berkisar dari status rendah sampai sedang. $\mathrm{N}$ total dengan status sedang berada pada kedalaman 0-30 cm. C/N rasio kurang dari 20 menunjukkan $\mathrm{N}$ tanah mudah termineralisasi. P Bray 1 umumnya berkisar sangat tinggi. KTK berkisar dari sedang sampai tinggi. KB umumnya masuk dalam status rendah.
Oksida Al dan Fe baik Al-, Fe-dithionite dan Al-, Fe-oksalat di Jawa Barat dan Jawa Tengah relatif sama. Semua lokasi Andisol menunjukkan salah satu sifat Andik yang merupakan ciri dari Andisol. Semua contoh tanah dari Andisol yang diteliti mampunyai nilai $\mathrm{Al}_{\mathrm{o}}+1 / 2 \mathrm{Fe}_{\mathrm{o}}$ lebih besar dari $2 \%$.

Variasi sifat fisikokimia Andisol di Jawa Barat dan Jawa Tengah diduga dipengaruhi oleh intensitas pemupukan dan pengaruh ketinggian dari permukaan laut serta faktor iklim seperti curah hujan yang lebih tinggi di Jawa Barat dibandingkan di Jawa Tengah. Nurwadjedi (2011) mengungkapkan bahwa distribusi tipe iklim di Jawa menunjukkan bahwa bagian barat Jawa memiliki bulan basah lebih banyak daripada bagian timur atau semakin ke timur lebih kering. Hal ini menyebabkan $\mathrm{pH}$ Andisol Dieng sedikit lebih tinggi dibandingkan dengan Andisol Jawa Barat.

\section{Pelepasan Nitrat}

Data pelepasan nitrat Andisol minggu ke-1, ke-2, ke-4 dan ke-6 disajikan pada Tabel 2. Pelepasan nitrat pada minggu ke-0 ditetapkan sebagai 0 . Tabel 2 menunjukkan bahwa pelepasan nitrat secara umum pada Andisol Lembang, Pangalengan, Sukamantri dan Dieng menurun dengan meningkatnya kedalaman tanah pada satu profil tanah dan meningkat dengan meningkatnya waktu inkubasi. Tabel 2 juga menunjukkan bahwa pelepasan nitrat dari paling tinggi sampai paling rendah selama inkubasi 6 minggu berturut-turut terdapat pada Andisol Dieng kedalaman 0-20 cm, Andisol Sukamantri kedalaman 0-10 $\mathrm{cm}$, Andisol Lembang kedalaman 16-36 cm, dan Andisol Pangalengan kedalaman 0-21 cm. Dari data tersebut menunjukkan bahwa pelepasan nitrat yang besar umumnya terjadi pada lapisan atas tanah dimana $\mathrm{C}$ organik dan $\mathrm{N}$ total relatif tinggi.

Tabel 1. Sifat fisikokimia Andisol di Jawa Barat dan Jawa Tengah

\begin{tabular}{|c|c|c|c|c|c|c|c|c|c|c|c|c|c|c|}
\hline Tanah & $\begin{array}{c}\text { Kedalam } \\
\text { an } \\
(\mathrm{cm}) \\
\end{array}$ & $\begin{array}{l}\text { Liat } \\
(\%)\end{array}$ & $\begin{array}{c}\mathrm{pH} \\
\mathrm{H}_{2} \mathrm{O} \\
(1: 5) \\
\end{array}$ & $\begin{array}{c}\mathrm{C}- \\
\text { organik } \\
(\%)\end{array}$ & $\begin{array}{c}\mathrm{N}- \\
\text { total } \\
(\%) \\
\end{array}$ & $\mathrm{C} / \mathrm{N}$ & $\begin{array}{c}\text { P-Bray 1 } \\
\left(\mathrm{mg} \mathrm{P}_{2} \mathrm{O}_{5}\right. \\
\left.\mathrm{kg}^{-1}\right)\end{array}$ & $\begin{array}{c}\text { KTK } \\
(\mathrm{me} \\
\left.100 \mathrm{~g}^{-1}\right)\end{array}$ & $\begin{array}{l}\mathrm{KB} \\
(\%)\end{array}$ & $\left.\begin{array}{c}\mathrm{Al} \\
\left(\mathrm{g} \mathrm{kg}^{-}\right. \\
1\end{array}\right)$ & $\begin{array}{c}\text { Feo } \\
\left(\mathrm{g} \mathrm{kg}^{-}\right. \\
1)\end{array}$ & $\begin{array}{c}\text { Alo }+1 / 2 \\
\text { Feo } \\
\left(\mathrm{g} \mathrm{kg}^{-1}\right)\end{array}$ & $\begin{array}{c}\text { Al-dd } \\
\left(\begin{array}{c}\mathrm{g} \mathrm{kg}^{-} \\
1\end{array}\right)\end{array}$ & $\begin{array}{c}\text { Fe-dd } \\
\left(\begin{array}{c}\mathrm{g} \mathrm{kg}^{-} \\
1\end{array}\right)\end{array}$ \\
\hline \multicolumn{15}{|c|}{ Jawa Barat } \\
\hline & $0-16$ & 41.6 & 5.46 & 7.25 & 0.54 & 13.3 & 63.9 & 35.3 & 17.4 & 40.5 & 5.55 & 43.3 & 3.83 & 33.4 \\
\hline Andisol & $16-36$ & 46.8 & 5.61 & 4.33 & 0.33 & 12.9 & 75.3 & 30.5 & 21.2 & 92.3 & 9.24 & 96.9 & 4.28 & 32.2 \\
\hline \multirow[t]{2}{*}{ Lembang } & $36-70$ & 46.2 & 5.27 & 7.86 & 0.28 & 28.2 & 80.0 & 30.6 & 32.4 & 74.9 & 8.71 & 79.2 & 6.08 & 37.0 \\
\hline & $70-100$ & 44.7 & 5.76 & 8.27 & 0.29 & 28.3 & 86.0 & 39.0 & 23.3 & 61.1 & 10.4 & 66.2 & 8.32 & 44.6 \\
\hline Andisol & $0-21$ & 35.9 & 5.94 & 8.16 & 0.61 & 13.3 & 57.1 & 34.9 & 27.9 & 21.7 & 9.79 & 26.6 & 4.50 & 30.3 \\
\hline \multirow{2}{*}{$\begin{array}{l}\text { Pangaleng } \\
\text { an }\end{array}$} & $21-52$ & 57.5 & 5.94 & 5.19 & 0.38 & 14.1 & 79.3 & 31.8 & 20.6 & 105 & 12.5 & 111 & 5.40 & 35.7 \\
\hline & $52-83$ & 62.3 & 5.87 & 3.35 & 0.24 & 13.7 & 96.5 & 21.4 & 22.4 & 91.0 & 15.5 & 98.7 & 4.28 & 35.9 \\
\hline Andisol & $0-10$ & 56.9 & 4.98 & 8.39 & 0.55 & 15.2 & 149 & 25.0 & 4.50 & 51.9 & 6.00 & 54.9 & 5.85 & 29.9 \\
\hline \multirow{2}{*}{$\begin{array}{c}\text { Sukamant } \\
\text { ri }\end{array}$} & $10-30$ & 44.9 & 5.38 & 7.29 & 0.38 & 18.9 & 76.4 & 21.5 & 3.00 & 43.5 & 5.66 & 46.3 & 3.82 & 32.9 \\
\hline & $41-50$ & 51.2 & 5.83 & 6.75 & 0.34 & 19.7 & 109 & 20.2 & 4.20 & 42.3 & 5.09 & 44.8 & 4.28 & 31.2 \\
\hline \multicolumn{15}{|c|}{ Jawa Tengah } \\
\hline \multirow{5}{*}{$\begin{array}{l}\text { Andisol } \\
\text { Dieng }\end{array}$} & $0-20$ & 20.3 & 5.72 & 6.29 & 0.45 & 14.0 & 127 & 33.7 & 34.9 & 43.5 & 9.87 & 48.4 & 3.38 & 44.3 \\
\hline & $20-33$ & 24.9 & 5.62 & 6.12 & 0.48 & 12.7 & 128 & 34.1 & 31.3 & 46.8 & 9.75 & 51.7 & 4.50 & 42.3 \\
\hline & $33-60$ & 29.4 & 5.57 & 3.57 & 0.22 & 15.9 & 81.2 & 22.0 & 36.7 & 57.6 & 9.30 & 62.3 & 3.38 & 42.0 \\
\hline & $60-82$ & 39.7 & 6.02 & 3.02 & 0.18 & 16.6 & 87.4 & 16.4 & 32.4 & 77.7 & 7.18 & 81.3 & 3.82 & 34.7 \\
\hline & $82-100$ & 40.3 & 6.31 & 2.66 & 0.15 & 17.3 & 78.1 & 16.3 & 35.6 & 72.3 & 7.67 & 76.1 & 3.38 & 36.8 \\
\hline
\end{tabular}


Tabel 2. Pelepasan nitrat (Nt) Andisol minggu ke-0 sampai dengan minggu ke-6

\begin{tabular}{|c|c|c|c|c|c|c|}
\hline \multirow{2}{*}{ Nama Tanah } & \multirow{2}{*}{$\begin{array}{l}\text { Kedalaman } \\
(\mathrm{cm})\end{array}$} & \multicolumn{5}{|c|}{ Pelepasan Nitrat $\left(\mathrm{mg} \mathrm{kg}^{-1}\right)$} \\
\hline & & 0 & 1 & 2 & 4 & 6 \\
\hline \multicolumn{7}{|c|}{ Jawa Barat } \\
\hline \multirow{4}{*}{ Andisol Lembang } & $0-16$ & 0 & 185 & 180 & 242 & 234 \\
\hline & $16-36$ & 0 & 554 & 599 & 708 & 825 \\
\hline & $36-70$ & 0 & 523 & 529 & 571 & 552 \\
\hline & $70-100$ & 0 & 482 & 529 & 587 & 628 \\
\hline \multirow{3}{*}{ Andisol Pangalengan } & $0-21$ & 0 & 337 & 385 & 407 & 435 \\
\hline & $21-52$ & 0 & 207 & 263 & 266 & 250 \\
\hline & $52-83$ & 0 & 286 & 371 & 369 & 385 \\
\hline \multirow{3}{*}{ Andisol Sukamantri } & $0-10$ & 0 & 840 & 783 & 875 & 985 \\
\hline & $10-30$ & 0 & 288 & 298 & 308 & 379 \\
\hline & $41-50$ & 0 & 250 & 248 & 243 & 328 \\
\hline \multicolumn{7}{|c|}{ Jawa Tengah } \\
\hline \multirow{5}{*}{ Andisol Dieng } & $0-20$ & 0 & 953 & 919 & 1,093 & 1,165 \\
\hline & $20-33$ & 0 & 590 & 630 & 645 & 830 \\
\hline & $33-60$ & 0 & 574 & 620 & 565 & 648 \\
\hline & $60-82$ & 0 & 543 & 592 & 598 & 659 \\
\hline & $82-100$ & 0 & 327 & 315 & 317 & 381 \\
\hline
\end{tabular}

Hasil simulasi data pelepasan nitrat $(N t)$ pada berbagai masa inkubasi $(t)$ dengan persamaan first order kinetics disajikan pada Tabel 3. Nilai $\mathrm{R}^{2}$ yang tinggi menunjukkan bahwa persamaan first order kinetics dapat digunakan untuk mendapatkan nilai $N_{O}$ (Nitrat maksimum yang dapat dilepaskan dalam $\mathrm{mg} \mathrm{kg}^{-1}$ ) dan $k$ (konstanta kecepatan pelepasan nitrat dalam minggu ${ }^{-1}$ ).

Nilai $N_{0}$ yang besar tidak berarti mempunyai nilai $k$ yang besar pula. Nilai korelasi antara $N_{0}$ dan $k$ relatif rendah yaitu 0.04. Hal ini berarti Andisol yang mempunyai jumlah maksimum nitrat yang dilepaskan besar belum tentu dilepaskan dengan kecepatan yang besar pula.

Tabel 3. Nilai $N_{0}$ (maksimum atau potensial nitrat yang dapat dilepaskan), $k$ (konstanta kecepatan pelepasan nitrat per minggu), dan $\mathrm{R}^{2}$ (koefisien determinasi) persamaan first order kinetics

\begin{tabular}{|c|c|c|c|c|}
\hline Nama Tanah & $\begin{array}{l}\text { Kedalaman } \\
\quad(\mathrm{cm})\end{array}$ & $\begin{array}{c}N_{0} \\
\left(\mathrm{mg} \mathrm{kg}^{-1}\right)\end{array}$ & $\begin{array}{c}k \\
\left(\operatorname{minggu}^{-1}\right)\end{array}$ & $\mathrm{R}^{2}$ \\
\hline \multicolumn{5}{|c|}{ Jawa Barat } \\
\hline \multirow{4}{*}{$\begin{array}{l}\text { Andisol } \\
\text { Lembang }\end{array}$} & $0-16$ & 229 & 1.33 & 0.9592 \\
\hline & $16-36$ & 759 & 1.08 & 0.9649 \\
\hline & $36-70$ & 552 & 2.85 & 0.9965 \\
\hline & $70-100$ & 597 & 1.50 & 0.9892 \\
\hline \multirow{3}{*}{$\begin{array}{c}\text { Andisol } \\
\text { Pangalengan }\end{array}$} & $0-21$ & 417 & 1.58 & 0.9949 \\
\hline & $21-52$ & 262 & 1.64 & 0.9943 \\
\hline & $52-83$ & 381 & 1.44 & 0.9973 \\
\hline \multirow{3}{*}{$\begin{array}{c}\text { Andisol } \\
\text { Sukamantri }\end{array}$} & $0-10$ & 887 & 2.68 & 0.9683 \\
\hline & $10-30$ & 334 & 1.78 & 0.9594 \\
\hline & $41-50$ & 276 & 2.15 & 0.9289 \\
\hline \multicolumn{5}{|c|}{ Jawa Tengah } \\
\hline \multirow{5}{*}{$\begin{array}{l}\text { Andisols } \\
\text { Dieng }\end{array}$} & $0-20$ & 1081 & 1.84 & 0.9695 \\
\hline & $20-33$ & 722 & 1.50 & 0.9463 \\
\hline & $33-60$ & 611 & 2.83 & 0.9877 \\
\hline & $60-82$ & 622 & 2.00 & 0.9921 \\
\hline & $82-100$ & 338 & 3.24 & 0.9698 \\
\hline
\end{tabular}

Persamaan first order kinetics yang menggambarkan hubungan waktu inkubasi dan nitrat yang dilepaskan disajikan pada Gambar 1. Pada Gambar tersebut dapat dilihat bahwa secara umum pelepasan nitrat maksimum sudah tercapai pada minggu ke 6 .

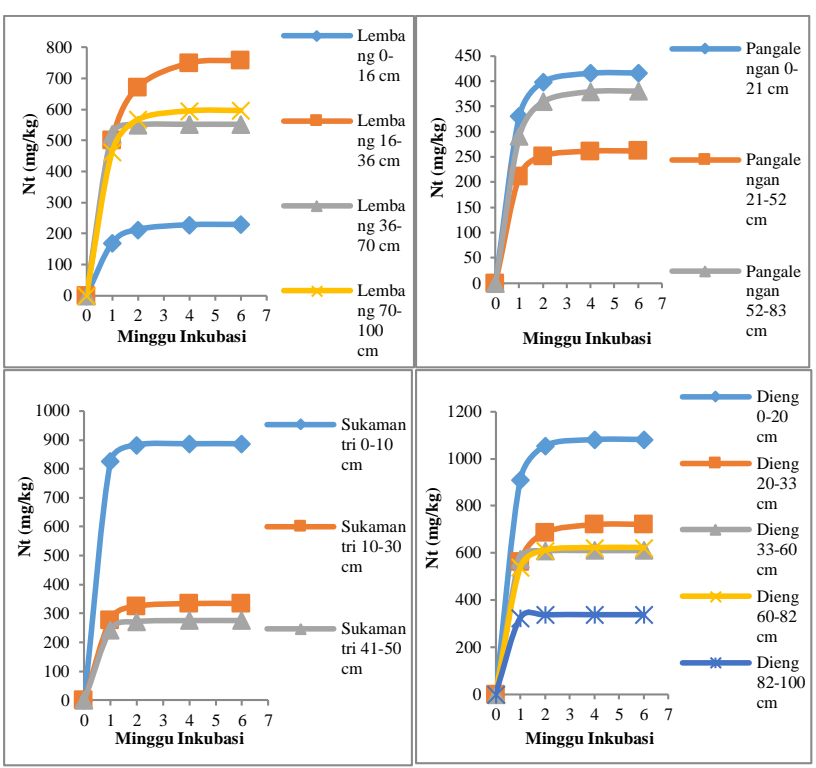

Gambar 1. Nilai $N t$ (nitrat yang dilepaskan pada waktu $t$ ) persamaan first order kinetics

\section{Hubungan Antara Nilai $N_{0}$ dan $\boldsymbol{k}$ Persamaan First Order Kinetics dengan Beberapa Sifat Kimia Tanah}

Hasil uji korelasi sederhana antara beberapa sifat kimia tanah Andisol dengan nilai $N_{0}$ dan $k$ persamaan first order kinetics disajikan pada Tabel 4. Nilai korelasi antara $N_{0}$ dan $k$ dengan sifat-sifat kimia tanah yang dianalisis relatif rendah. Hal ini menunjukkan bahwa keberadaan nitrat di dalam tanah tidak hanya dipengaruhi oleh sifat kimia tanah akan tetapi juga dipengaruhi sifat tanah lainnya seperti sifat biologi tanah. Selain itu nitrat sangat mobil di dalam tanah dimana korelasi dengan oksida-oksida Al dan Fe relatif rendah. Walaupun demikian hasil analisis korelasi menunjukkan bahwa untuk $N_{0}$ memiliki korelasi positif dengan $\mathrm{C}$ orgnaik tanah, $\mathrm{N}$ total, Fe-oksalat, Al-dithionite, dan Fe-dithionite serta memiliki korelasi negatif dengan $\mathrm{Al}$ oksalat dan $\mathrm{Al}_{\mathrm{o}}+1 / 2 \mathrm{Fe}_{\mathrm{o}}$. Sedangkan untuk $\mathrm{k}$ hanya memiliki korelasi positif dengan $\mathrm{Fe}$ dithionite.

Hasil ini menunjukkan bahwa pelepasan nitrat pada Andisol punya kemungkinan meningkat dengan meningkatnya kadar $\mathrm{C}$ organik dan $\mathrm{N}$ total tanah akan tetapi menurun dengan meningkatnya $\mathrm{Al}_{\mathrm{o}}+1 / 2 \mathrm{Fe}_{\mathrm{o}} . \mathrm{Al}_{\mathrm{o}}+1 / 2 \mathrm{Fe}_{\mathrm{o}}$ juga mempunyai kemungkinan menurunkan kecepatan pelepasan nitrat pada Andisol.

Tabel 4. Korelasi antara beberapa sifat kimia tanah dengan nilai $N_{o}$ dan $k$ persamaan first order kinetics

\begin{tabular}{rccccccc}
\hline & $\begin{array}{c}\mathrm{C} \\
\text { organik }\end{array}$ & $\begin{array}{c}\mathrm{N} \\
\text { total }\end{array}$ & Alo & $\mathrm{Feo}$ & $\begin{array}{c}\mathrm{Alo}+1 / 2 \\
\mathrm{Feo}\end{array}$ & $\mathrm{Al}_{\mathrm{d}}$ & $\mathrm{Fe}_{\mathrm{d}}$ \\
\hline$N_{0}$ & 0.080 & 0.142 & -0.081 & 0.054 & -0.075 & 0.072 & 0.394 \\
$k$ & -0.153 & -0.387 & -0.016 & -0.312 & -0.033 & -0.097 & 0.039 \\
\hline
\end{tabular}

\section{SIMPULAN}

Berdasarkan hasil analisis, sifat-sifat kimia tanah Andisol di Jawa Barat dan Jawa Tengah sangat bervariasi. Pelepasan nitrat paling besar terjadi pada lapisan atas tanah. Tanah dengan nilai pelepasan nitrat maksimum besar belum tentu diikuti dengan nilai konstanta kecepatan pelepasan nitrat yang besar pula.

Kadar $\mathrm{C}$ organik dan $\mathrm{N}$ total mempunyai kemungkinan meningkatkan jumlah nitrat yang dilepaskan. 
Salah satu sifat andik yaitu nilai $\mathrm{Al}_{\mathrm{o}}+1 / 2 \mathrm{Fe}_{\mathrm{o}}$ mempunyai kemungkinan menurunkan jumlah maksimum nitrat yang dilepaskan dan kecepatan pelepasannya.

\section{DAFTAR PUSTAKA}

Balai Penelitian Tanah. 2009. Analisis Kimia Tanah, Tanaman, Air, dan Pupuk. Balai Penelitian Tanah, Bogor.

Hartono, A., S. Anwar, dan C.M. Lutfi. 2007. Studi erapan fosfor, belerang dan boron pada tanah Andisol Sukamantri, Latosol Darmaga dan Grumusol Cihea. Prosiding Seminar Kongres Nasional IX HITI.

Hartono, A. 2008. The effect of calcium silicate on the phosphorus sorption characteristics of Andisols Lembang. J. Tanah Lingk., 10(1):14-19.

Hartono, A. dan R. Bilhaq. 2011. Pengaruh silikat terhadap pola pelepasan fosfor Andisol Lembang dengan menggunakan successive Resin Extraction. Prosiding Seminar Kongres Nasional X HITI.

McKeague, J.A. and J.H. Day. 1966. Dithionite and oxalate extractable $\mathrm{Fe}$ and $\mathrm{Al}$ as aids in differentiating various classes of soils. Can. J. Soil Sci., 46:13-22.
Mehra, P.O. and M.L. Jackson. 1960. Iron oxide removal from soils and clays by dithionite-citrate system buffered with sodium bicarbonate. Clays Clay Miner, 7:317-327.

Nurwadjedi. 2011. Indeks keberlanjutan lahan sawah untuk mendukung penataan ruang: studi kasus di Pulau Jawa [Disertasi]. Fakultas Pascasarjana, Institut Pertanian Bogor, Bogor

[Puslittanak] Pusat Penelitian Tanah dan Agroklimat. 2000. Atlas Sumberdaya Tanah Eksplorasi Indonesia, Berwarna Skala 1:1,000,000. Publikasi Puslittanak. Badan Litbang Pertanian, Bogor.

Saito, M. and K. Ishii. 1987. Estimation of soil nitrogen mineralization in corn-grown fields based on mineralization parameters. Soil Sci. Plant Nutr., 33:555-566.

Sano, S., J. Yanai, and T. Kosaki. 2004. Evaluation of soil nitrogen status in Japanese agricultural lands with reference to land use and soil types. Soil Sci. Plant Nutr., 50:501-510.

Stanford, G. and S.J. Smith. 1972. Nitrogen mineralization potentials of soils. Soil Sci. Soc. Am. J., 36:465-472. 